\title{
O CONCEITO DE FORMAÇÃO ESPACIAL: SUA GÊNESE E CONTRIBUIÇÃO PARA A GEOGRAFIA
}

\author{
MARIA CLARA DA CRUZ*
}

\section{Introdução}

O estudo do espaço tem sido uma das questões cruciais em debate na Geografia. Essa compreensão implica analisar os processos e as peças que constituem o espaço e o seu dinamismo, assim como desvendar um conjunto de correntes ou posicionamentos teórico-metodológicos os quais constituem expressões de sistemas filosóficos e de ideologias diferenciadas as quais assumem linguagens específicas no campo da ciência.

Os conceitos relativos ao espaço traduzem um determinado posicionamento político e ideológico do geógrafo inserido em um contexto histórico-social e geográfico específico. Estes conceitos representam meios de abordar problemas específicos não compreendidos em sua totalidade por paradigmas anteriores.

O conceito de formação espacial nasce como resultado da tentativa de superar a influência de um sistema filosófico idealista sobre a Geografia. Considerada uma adaptação da categoria de formação econômica e social, a concepção de formação espacial passa a ser um dos instrumentos de análise do espaço sob a ótica da dialética marxista e do materialismo histórico.

Doutoranda do Programa de Pós-Graduação em Geografia da UFRJ. 
Desenvolvido durante a década de 1970, o conceito de formação espacial atribui ao espaço um status de condição básica para a viabilização da produção. As diferenciações entre os lugares tornam-se expressão de diferentes formações econômicas sociais representativas de modos de produção específicos. Neste sentido, este trabalho propõe realizar uma análise do conceito de formação espacial através de sua gênese e de sua contribuição para a Geografia.

\section{A Gênese do Conceito}

Analisar o conceito através de sua gênese implica compreender as bases teóricas e metodológicas responsáveis pela construção da concepção de formação espacial. Sob esta ótica, ressaltam-se dois direcionamentos teórico-metodológicos interdependentes: o pensamento marxista, através de sua dialética e do materialismo histórico; e o pensamento estruturalista como uma tentativa de relacionar os conceitos de modo de produção e formação econômica e social. A aplicação destas visões proporciona uma nova ótica para a compreensão do espaço inserindo-o em uma totalidade sócio-espacial.

\section{O Materialismo Histórico e a Dialética Marxista}

Existe uma ênfase em considerar a obra de Karl Marx (1818-1883) e Friedrich Engels (1820-1895) como uma reação ao pensamento de Georg W. Hegel (17701831) e à sua influência no século XIX. A filosofia marxista é frequëntemente considerada como ponto de partida para a crítica à filosofia hegeliana pois visa superar a concepção de idéia, substituindo-a pela de matéria ou real. (Quaini, 1979).

Marx e Engels (1986) argumentam que a substantificação da idéia transforma o sujeito real em um predicado ou atributo desta, eliminando-se as diferenças entre idéia e real. No sentido de se evitar este problema, o sistema filosófico materialista propõe voltar da abstração para o empírico. No entanto, esse método é dialético. A superação da abstração ocorre apenas na aparência, pois existe a necessidade de se considerar a substância (QUAINI, 1979).

A superação da concepção de idéia leva à adoção da dialética da matéria (do real) como unidade básica de análise. A concepção materialista torna-se ponto de partida para o sistema filosófico marxista. O método proposto passa a ser dotado de premissas reais, resultantes de sua atividade intrínseca e de suas condições materiais (MARX e ENGELS, 1986):

- o ponto básico constitui a organização dos indivíduos humanos e sua relação com o restante da natureza;

- a história deve sempre expressar estas bases e suas modificações através daś ações humanas; 
- os homens se caracterizam pela sua capacidade de produção de suas formas de subsistência através da qual estão indiretamente produzindo sua vida material (modo de produção);

- o modo de produção deve ser considerado como a forma como ocorre a produção (como eles produzem) e o resultado da produção (o que eles produzem);

- as relações entre os indivíduos são determinadas pela produção.

A produção constitui, dentro deste contexto, a unidade mediadora das relações sociais. Através da análise da produção em uma escala espaço-temporal integrada, o método materialista acaba por apresentar uma proposta de explicação teórica para a compreensão da sociedade através do entendimento das relações entre os lugares, da estrutura interna dos lugares e do desenvolvimento interno entre os lugares.

"Não somente as relações de uma nação para outras, mas também toda a estrutura interna da nação em si depende do estágio de desenvolvimento alcançado pela sua produção e suas relações internas e externas". ( MARX e ENGELS, 1986:43)

Deve-se enfatizar que, nèste sentido, a filosofia marxista passa a se conectar com uma tradição de pensadores utilizadores da história como instrumento de análise (QUAINI, 1979). A diferenciação com relação a estes sistemas filosóficos consiste em entender o movimento da história como uma dimensão do movimento da matéria.

"O fato de que Hegel constrói tais formas históricas como tipos históricos objetivos (isto é, como valor de 'modelos') parece estar em relação com o historicismo iluminista de Montesquieu que está, por sua vez, na origem da fecunda escola 'histórico-sociológica escocesa'. O interesse comum desta escola está de fato voltado àquela 'natural history of society', por enquanto 'história teórica' ou tentativa de utilizar conceitos que consistem em classificações históricas que permitem articular várias épocas da história à base de 'tipos' ou 'modelos' de sociedade". (QUAINI, 1979:41).

Embora influenciado pela tradição historicista, o materialismo rompe com a concepção de tipos e modelos. Na concepção materialista espaço e tempo constituem categorias objetivas com existência independente da consciência humana. As propriedades de espaço e de tempo são determinadas pela natureza da própria matéria (OLIVEIRA, 1982).

O materialismo histórico representa, portanto, uma proposta de análise baseada nas condições reais da materialidade. A formação econômica e social constitui uma categoria básica de análise deste método. A sistematização desta categoria e sua relação com as estruturas de produção trazem uma nova dimensão para o pensamento marxista.

\section{O Estruturalismo}

O materialismo histórico e a dialética marxista integram um sistema filosófićo baseado no movimento dinâmico e dialético da matéria analisado através dos diver- 
sos estágios da produção humana. Sobre esta perspectiva, a filosofia marxista estabelece uma distinção entre (HAMLYN, 1987):

- a base (infra-estrutura) como o sistema de relações econômicas e forças produtivas;

- a superestrutura (ideologia) como as instituições jurídicas e o sistema de crenças.

Deve-se considerar, incialmente, que o pensamento estruturalista não se encontra restrito à filosofia marxista. No caso das ciências sociais, a construção do pensamento estruturalista contou com a participação de visões não materialistas elaboradas por Émile Durkheim (1858-1917) e Claude Lévy-Strauss (GREGORY, 1978). O encontro do estruturalismo e do marxismo está representado na obra de Louis Althusser (1918-1990) (GREGORY, 1978). Sua contribuição consiste em uma visão mais sistematizada do conceito de modo-de-produção e sua relação com o conceito de formação econômica e social e, posteriormente, com o conceito de formação espacial.

A leitura de Louis Althusser da obra de Marx constitui uma explicação estruturalista do materialismo histórico e da dialética marxista. Para Althusser, o conceito de modo de produção é a base para a compreensão da estruturação (GREGORY, 1978). Este processo pode ser utilizado para explicar o movimento real do mundo social. A ideologia (super-estrutura) atua na manifestação das aparências da-sociedade e as reproduz como categorias em um discurso não examinado.

A ideologia legitima uma forma particular de conhecimento e uma forma particular de existência do mundo (GREGORY, 1978). Na leitura althusseriana de Marx existem três níveis de compreensão: o econômico, o político e o ideológico. $\mathrm{O}$ nível econômico constitui o meio através do qual a força de trabalho usa os meios de produção para transformar o objeto de trabalho. Essa concepção de modo de produção é dinâmica, pois é constituída pelo processo de estruturação o qual se realiza mediante a interação entre o homem e a natureza e mediante a criação de uma reserva de valor decorrente da realização do trabalho (GREGORY, 1978).

Entende-se, portanto, que a diferenciação entre os modos de produção se manifesta pelos diferentes tipos de articulação entre o nível econômico, o nível ideológico e o nível político. Para Althusser, o nível econômico exerce predominância sobre os demais (GREGORY, 1978). Neste sentido, o padrão das relações econômicas e das forças produtivas é responsável pela superestrutura, definindo-se, assim, o modo de produção.

A concepção de Althusser sobre modo de produção constitui a base para a construção da categoria de formação econômica e social, a qual será aplicada na Geografia para a elaboração de formação espacial. Nesta abordagem, as estruturas sociais se expressam em estruturas espaciais (GREGORY, 1978). Portanto, deve-se considerar que as relações sociais resultantes das relações econômicas se encontram representadas no espaço de acordo com a lógica e as contradições do modo de produção dominante. 


\section{O Conceito de Formação Espacial}

A definição estruturalista de modo de produção está relacionada com a categoria de formação econômica e social e com o conceito de formação espacial. De acordo com esta concepção, o sistema de relações econômicas (a infra-estrutura) determina as condições da superestrutura (o sistema político e ideológico).

Enquanto o modo de produção constitui um modelo de realização do trabalho, um padrão de relação econômica e social, a formação econômica e social constitui a realização concreta da produção com sua lógica e com suas contradições. Esta distinção não implica a inexistência de relação entre os conceitos. Ao contrário, a definição de um depende das características do outro, através do estabelecimento de uma relação dialética entre as duas categorias de análise.

"Aqui, a distinção entre modo de produção e formação social aparece como necessidade metodológica. O modo de produção seria o 'gênero' cujas formações sociais seriam as 'espécies'. O modo de produção seria apenas uma possibilidade e somente a formação econômica e social seria possibilidade realizada". (SANTOS, 1979)

Neste sentido, o real desenvolvimento de um modo de produção constitui a formação econômica e social. No entanto, considerando-se que a produção implica "a organização dos indivíduos humanos e sua relação com o restante da națureza" (MARX e ENGELS, 1986) e que a formação econômica e social constitui a "estrutura técnica produtiva expressa geograficamente na distribuição da produção" (SANTOS, 1979), o espaço constitui um elemento-chave no processo de formação econômica e social.

A necessidade de inserir o espaço como categoria de análise, juntamente com a formação econômica e social justifica-se, pois em uma sociedade (SANTOS, 1979):

- existe uma descontinuidade no desenvolvimento histórico;

- a formação econômica e social, por sua vez, expressa a unidade e a totalidade da infra-estrutura e da super-estrutura (esferas econômica, social, política e cultural);

- no entanto, existe uma determinação específica das variações da existência histórica.

As "variações da existência histórica" constituem o arranjo geográfico resultante do modo de socialização da natureza (MOREIRA, 1982). Este processo se desenvolve a partir de uma estrutura de relações nas quais o espaço constitui um mediador fundamental.

A relação homem/meio, ao ser traduzida na relação história/natureza resulta no desenvolvimento de uma totalidade estruturada em múltiplas relações (MOREIRA, 1982). A história dos homens constitui a história da transformação permanente acumulativa da natureza pelo processo de trabalho.

O trabalho é responsável pela transformação de uma totalidade estruturada por elementos naturais (primeira natureza) em uma segunda natureza, ou seja, em uma 
totalidade estruturada sobre determinações de um espaço social - o espaço geográfico concreto (MOREIRA, 1982).

A formação espacial é, portanto, a expressão fenomêmica de um sistema de relações sociais (MOREIRA, 1982). Sob esta perspectiva, quando, através da socialização da natureza, é gerado um sistema de diferenciação de classes sociais, o espaço passa a constituir uma das dimensões reveladoras desta diferenciação.

Mas então como a categoria de formação espacial torna-se relevante para a Geografia? Como ela torna-se um instrumento de análise?

Inicialmente, as descontinuidades e as unidades sócio-espaciais fundam-se sobre um quadro geográfico reconhecível e sobre as interrelações estabelecidas entre o espaço e a sociedade (DI MÉO, 1985). A formação espacial é a possibilidade metodológica de apresentar a dimensão espacial como a expressão da relação entre a infra-estrutura e a super-estrutura.

Em segundo lugar, as descontinuidades espaciais não implicam a ausência de interrelação entre as diferentes formas espaciais (SANTOS, 1979). A formação espacial permite a análise da totalidade sócio-espacial hierarquizada, constituindo um sistema cujas partes constituem organismos interdependentes (DI MÉO, 1985).

A formação espacial pode ser considerada, portanto, um instrumento de análise cuja utilização pela Geografia permite a compreensão de processos complexos. Este conceito permite uma abordagem totalizante para questões cujo entendimento demanda uma perspectiva integradora e não dicotômica.

\section{A Contribuição para a Geografia}

O conceito de formação espacial nasce associado à categoria de formação econômica e social cuja origem encontra-se no materialismo histórico e na dialética marxista. O entendimento do impacto desta concepção sobre a Geografia implica analisar, inicialmente, o contexto do pensamento geográfico anterior à introdução do conceito de formação espacial, um contexto dominado por uma concepção idealista e positivista.

Também se deve avaliar a importância da concepção de formação espacial para os estudos da Geografia brasileira. Esta análise visa, em última instância, demonstrar que o conceito tem a sua origem e a sua utilização associadas a um contexto histórico e geográfico específicos, a um determinado momento na Geografia.

\section{Os Antecedentes da Geografia}

Se o conceito de formação espacial resulta de uma tentativa de aplicação do materialismo histórico e da dialética marxista na Geografia, o impacto de sua utilização só pode ser avaliado através da compreensão do contexto do pensamento geo- 
gráfico anterior à sua elaboração. Pode-se considerar que a Geografia, principalmente durante os séculos XIX e XX, esteve sujeita às influências de um conjunto de sistemas filosóficos. Dentre estes, destaca-se o idealismo kantiano (GOMES, 1996) e o positivismo. (GREGORY, 1978).

Deve-se ressaltar que as implicações do idealismo e do positivismo sobre a Geografia não ocorrem de forma direta. $\mathrm{Na}$ verdade, o processo é mais complexo, na medida em que a Geografia resulta de uma série de decisões tomadas em situações históricas particulares por um número relativamente pequeno de "homens ocupando posições de autoridade e prestígio" (GREGORY, 1978). As diversas correntes do pensamento geográfico traduzem, em última instância, visões particulares e ecléticas (GOMES, 1996).

A influência do filósofo alemão Immanuel Kant (1724-1804) é decisiva para a Geografia que se iniciava em fins do século XVIII. Na filosofia kantiana a natureza é considerada segundo o aspecto da externalidade dos objetos. A apreensão da natureza é realizada através da intuição, ou seja, o encontro fenomenal guiado por intermédio das representações dos objetos (conceitos). A Geografia, neste sentido, constitui o esforço na busca do estabelecimento de relações espaciais entre diversos fenômenos apreendidos através de experiências guiadas por conceitos logicamente arranjados no pensamento (GOMES, 1996).

A Geografia, por outro lado, encontrava-se inserida na revolução científica iniciada no século XVIII. A vontade de substituir a "dimensão metafísica e mística da pesquisa por uma legitimidade epistemológica centrada nos meios e de assegurar a validade de seus métodos" (GOMES, 1996). Neste sentido, a filosofia positivista de Augusto Comte (1798-1857) representa para a Geografia a possibilidade de afirmar proposições a partir de um certo grau de precisão dentro dos limites de uma linguagem lógica (GOMES, 1996) tendo como premissas o análise do real, a certeza, a precisão e a relatividade (GREGORY, 1978).

Deve-se considerar que as principais correntes do pensamento geográfico no decorrer dos séculos XIX e XX aplicaram tanto os preceitos do idealismo kantiano quanto do positivismo. No entanto, este processo realizou-se através de uma forma indireta e complexa, no qual são observadas influências de outros sistemas filosóficos ou teorias de outras ciências.

Para Alexander von Humboldt (1769-1859), considerado um dos fundadores da Geografia moderna, o método em Geografia deveria estar baseado na observação direta, na descrição detalhada e na preocupação permanente em se proceder a comparações e a raciocínios gerais e evolutivos (GOMES, 1996). O método proposto por Humboldt é influenciado pelo idealismo alemão através da Filosofia da Nature$z a$. cuja premissa básica é a observação da natureza como a origem do conhecimento.

Carl Ritter (1779-1859), considerava a Geografia de sua época como um "conjunto desordenado de dados" com um precário suporte teórico para o qual era necessárió delimitar o objeto e estabelecer novas bases para um saber organizado e rigoroso para 
o estudo da natureza (GOMES, 1996). Essa concepção é influenciada pelo pensamento de Friedrich W. Schelling (1775-1854), para quem o conhecimento da natureza só era possível mediante a utilização de um princípio de ordem geral, um plano teleológico dado pelo todo orgânico, e pela hermenêutiva de Friedrich August Wolf, baseada na contextualização da produção de textos através do uso de analogias e comparações para a interpretação, sem que seja perdida a perspectiva do conjunto.

A obra de Paul Vidal de La Blache (1845-1918) estruturou-se a partir da conjunção de diversas influências (Aristóteles, Kant, Schelling e Hegel) para a construção de uma concepção de Geografia diferenciada. Neste sentido, a influência de Kant manifesta-se principalmente na visão da necessidade de se impor limites para a atividade racional e em sua possibilidade de alcançar a essência das coisas. Este relativismo científico seria utilizado como uma forma de questionar a certeza e o conhecimento, os quais estariam inscritos dos dados de uma experiência relativa ao fenômeno através da descrição, da explicação, da comparação e da conclusão definindo-se como categorias de análise o organismo, o meio, a ação humana e o gênero de vida (GOMES, 1996).

O determinismo, por sua vez, como uma expressão do pensamento positivista, iria ter uma influência decisiva na Geografia (GOMES, 1996). O pensamento determinista (muito mais abrangente do que o determinismo de Ratzel) propõe-se a ser uma metodologia baseada no conhecimento positivo (que conduz à verdade) e um instrumento de precisão (ciência normativa).

A principal expressão do determinismo constitui a teoria evolucionista de Charles Darwin (1809-1882) a qual serviu de base para a elaboração do pensamento determinista de Friedrich Ratzel (1844-1904). Esta concepção tem como objetivo traçar um quadro geral ou um modelo para diversas dinâmicas territoriais (GOMES, 1996). Neste sentido, Ratzel, ao utilizar as teorias da Biologia (que na segunda metade do século XIX constituía um novo paradigma em evidência) coloca a Geografia na modernidade científica (GOMES, 1996).

Deve-se considerar que, por estabelecer relações de causa e efeito e definir categorias gerais para o estudo de casos concretos; o determinismo desdobrou-se em outras correntes de pensamento (GOMES, 1996). Dentre estas concepções, destacam-se as próprias aplicações dos preceitos do positivismo em Geografia durante o século XX como pode ser observado nos trabalhos de Carl O. Sauer (1889-1975) e Richard Hartshorne (1899-1992) (GREGORY, 1978).

Sauer entende a Geografia como a ciência que "descobre o campo sob o relevo" (GREGORY, 1978). Neste sentido, seu objetivo é desvendar a organização sistemática do conteúdo através do estabelecimento das conexões existentes no fenômeno segundo os princípios metodológicos inerentes ao rigor científico (GREGORY, 1978).

Hartshorne, por sua vez entende a Geografia como o estudo das forças que não podem ser vistas, ou observadas diretamente. A análise da manifestação dos fatores que atuam na área seria realizada atavés da utilização de abstrações e princípios genéricos (GREGORY, 1978). 
O trabalho de Schaefer, desenvolvido em oposição a Hartshorne, lança bases para a aplicação do positivismo lógico nos estudos geográficos. Para Schaefer, a Geografia deveria sempre romper com as atitudes históricas às quais se encontrava associada para passar para uma perspectiva moderna cuja identidade metodológica deveria ser compartilhada com outras disciplinas (GOMES, 1996).

A partir da concepção de Schaefer, a Geografia passa a adotar proposições de caráter dedutivo inerentes às ciências formais (a matemática e a lógica). Este procedimento representa um distanciamento da tradição geográfica em trabalhar com procedimentos menos formais e indutivos (GREGORY, 1978).

A conjunção do positivismo com outras correntes do pensamento, representou o desdobramento de várias teorias diferenciadas. O marxismo, como um sistema filosófico de posicionamento determinista (GOMES, 1996) levou à elaboração de novos conceitos e novas teorias. A grande particularidade da aplicação do materialismo histórico e da dialética marxista encontra-se na sua visão materialista e não idealista da realidade, a qual retira todo o aspecto místico, religioso e de abstração para uma compreensão científica das relações entre natureza, produção e sociedade.

\section{A Contribuição da Geografia Critica}

De acordo com SANTOS (1978), qualquer categoria de análise tem sua existência associada à conjunção histórica de várias circunstâncias que tornam a sua utilização mais adequada. A introdução do conceito de formação espacial na Geografia integra um momento caracterizado como a consolidação da dialética marxista e do materialismo histórico enquanto alternativas metodológicas no pensamento geográfico. Este processo não se deu de forma homogênea, mas originou um conjunto de correntes teóricas as quais passaram a ser identificadas como parte da Geografia Marxista (SOJA, 1993) ou da Geografia da Crítica Radical (GOMES, 1996).

Os fatores responsáveis pelo surgimento desta corrente estão relacionados principalmente às limitações apresentadas pela abordagem positivista na Geografia a qual se tornara hegemônica a partir do fim da Segunda Guerra Mundial (GOMES, 1996).

A necessidade de buscar outros direcionamentos teórico-metodológicos levou, principalmente, à construção de uma nova visão sobre o espaço. Neste sentido, torna-se fundamental a contribuição do pensamento marxista (sobretudo o desenvolvido na França) a partir da primeira metade do século XX. Este período pode ser considerado como a retomada da espacialidade enquanto uma categoria relevante a ser analisada no pensamento marxista (SOJA, 1993).

O filósofo francês Henri Lefébvre (1901-1991) torna-se um dos expoentes desse debate, constituindo o principal defensor da reafirmação do espaço. No entanto, seu posicionamento frente à espacialidade estava mais próximo da dialética hegeliana do que do materialismo histórico. Embora Lefebvre aceitasse a primazia da vida material na produção do pensamento e da ação consciente, ele recusava a redução do 
pensamento como um todo a um "determinado retoque posterior ou a uma ideação mecânica" (SOJA, 1993). Considera-se, portanto, que Lefebvre tenha sucumbido ao "fetchismo" do espaço, pois sua concepção estava associada a uma estrutura de relações espaciais autônomas da história e da ação humana (SOJA, 1980).

Os trabalhos desenvolvidos pela geografia inglesa a partir da década de 1970 tornam-se responsáveis pela religação entre forma espacial e processo social (Soja, 1993). O materialismo histórico torna-se o método utilizado por David Harvey para combinar a Geografia Humana com a análise das classes e com a descrição dos efeitos geográficos utilizando informações fornecidas por uma economia política marxista. Em sua obra A Justiça social e a Cidade Harvey considera as formas espaciais não como objetos inanimados, mas como coisas que contêm processos sociais, da mesma forma que são por estes contidas:

“A abordagem adotada é que uma vez que nós descobrimos o que o espaço é e tendo descoberto formas de representá-lo, então nós podemos prosseguir com nossa análise do fenômeno urbano através da adequaşão do nosso entendimento do comportamento humano em alguma concepção geral de espaço". (HARVEY, 1973:13).

Dentro desse contexto, a Geografia Marxista se desenvolve no decorrer da década de 1970 através de três variações, embora em alguns momentos, interpenetradas (SOJA, 1993):

- a primeira, britânica, rigidamente historicista, sem teorização especulativa;

- a segunda, o neomarxismo desenvolvido no continente americano voltado para atualizar os princípios marxistas;

- a terceira baseada na tradição francesa e influenciada pelo estruturalismo e pelo existencialismo, constituindo a principal fonte inspiradora do neomarxismo.

A leitura estruturalista passa a representar uma racionalização epistemológica. Este direcionamento teórico-metodológico tem a função de descobrir as raízes explicativas nas relações de produção sociais estruturadas e estruturantes (SOJA, 1993). A análise estruturalista torna-se o principal método de análise pelo sociólogo espanhol Manuel Castells em sua obra A Questão Urbana, de 1972, na qual é desenvolvida uma caracterização espacial dos três níveis do modo de produção: o econômico, o político e o ideológico (GREGORY, 1978).

A influência estruturalista sobre a obra de Milton Santos encontra-se no desenvolvimento de um arcabouço teórico-conceitual elaborado a partir da categoria de formação econômica e social. Esta é resultado de um momento histórico específico no qual ocorrem, simultaneamente "o agravamento das dependências, a individualização das estruturas sócio-econômicas nacionais causada pela internalização de processos externos e pela externalização de processos internos" " (SANTOS, 1978). 
Para Santos, a categoria de formação econômica e social só pode ser analisada através da noção de totalidade na qual a ordem espacial é paralela à ordem econômica, social e política. Neste sentido, as formações econômicas e sociais existem devido aos seus aspectos concretos que permitem levar em conta a especificidade de cada sociedade tomada como uma realidade historicamente determinada e fundada sobre uma base territorial:

\begin{abstract}
"Seria, entretanto, um erro formidável considerar a renda da terra, ou a forma tomada pela mais-valia ou a expressão geográfica de luta de classes, ou o papel ideológico da arquitetura e do urbanismo etc., como se cada uma destas categorias não se apresentasse como o que ela realmente é, quer dizer, um momento, uma região da realidade total, uma estrutura subordinada e autônoma ao mesmo tempo, autônoma pelo fato de estar dotada de determinações que lhe são próprias". (SANTOS. 1978:141)
\end{abstract}

A partir da identificação do processo social como, também, um processo espacial, Santos propõe o conceito de formação sócio-espacial (ou formação espacial) como o mais adequado a ser utilizado pela Geografia. Neste contexto, a Geografia constitui, através da noção de totalidade, o estudo das sociedades humanas em sua obra de permanente reconstrução de espaço herdado das gerações precedentes (SANTOS, 1978).

O conceito de formação espacial tem, portanto, sua gênese inerente a um momento específico na Geografia. Um momento de introdução do materialismo histórico e da dialética marxista como métodos de análise, assim como da utilização da interpretação estruturalista como sistematização desta análise. Pode-se considerar a existência de outras abordagens com um direcionamento teórico-metodológico semeIhante. Isto não implica, necessariamente a utilização do conceito de formação espacial, mas uma aproximação da visão do que é espaço.

SOJA (1980), após uma análise crítica dos trabalhos de Lefebvre e Harvey, passa a propor o conceito de dialética sócio-espacial. De acordo com esta concepção, a estrutura do espaço organizado não está separada das outras com suas próprias leis autônomas de construção e transformação (como em Lefebvre); nem é simplesmente uma expressão da estrutura de classes (como em Harvey). A estrutura espacial representa um componente dialeticamente definido pelas relações sociais e espaciais de produção.

DI MÉO (1985), entende que, além das instâncias econômicas e político-ideológicas existem as instâncias geográficas como determinações das formações sócioespaciais. Estas instâncias são expressas através da associação interativa da natureza e das realizações humanas, traduzidas pelo processo simultâneo de ocupação e produção do espaço. Este constitui, por fim, um produto sócio-econômico herdado da história e aberto à mudança social.

A diferenciação conceitual não exclui a importância das implicações da concepção do espaço enquanto uma dimensão da totalidade social. A formação espacial 
passa a ser um conceito cuja operacionalzação vai demandar a utilização de um método específico.

\section{A Aplicação na Geografia Brasileira}

Em um artigo intitulado A Formação Social como Teoria e como Método, de 1996, Armen Mamingonian discute a necessidade de se retomar o debate em torno da categoria de formação social (ou formação econômica e social). O conceito de formação espacial derivado desta categoria torna-se praticamente ignorado pelos principais autores que tratam do espaço (como Soja e Castells), e pela Geografia Física em geral a qual continua trabalhando com uma visão dicotomizada de espaço e natureza (MAMINGONIAN, 1996).

Esta preocupação tem sua origem na ausência do aprofundamento da utilização do conceito de formação espacial na Geografia brasileira. Pradoxalmente, na Geografia em geral, o período posterior à década de 1980 é marcado pelo desenvolvimento de um debate crítico mais amplo e profundo sobre a teorização adequada da espacialidade da vida social. Também é caracterizado pelo questionamento das tradições do marxismo, passando para a afirmação de um materialismo histórico profundamente espacializado.

No caso brasileiro, um dos trabalhos mais contundentes, realizado de acordo com a visão marxista é anterior ao surgimento do conceito de formação espacial, A Formação do Brasil Contemporâneo, de Caio Prado Júnior. Publicada originalmente em 1942, tem por objetivo compreender o Brasil através da evolução histórica de sua organização sócio-econômica:

A especificidade dessa obra consiste em abordar a história colonial brasileira dentro da visão de totalidade abrangendo os aspectos estruturais (econômicos, políticos e ideológicos) com seus conflitos e contradições. Este trabalho serve de base para o desenvolvimento de uma Geografia Marxista brasileira a qual culmina no trabalho de Milton Santos (Mamingonian, 1996).

Pode-se considerar que a introdução do conceito de formação espacial é acompanhada de duas categorias de produção científica na Geografia brasileira. A primeira, composta por trabalhos de caráter mais teórico e a segunda, constituída por aplicações mais empíricas do método inerente ao conceito.

Dentre as formulações teóricas encontram-se as propostas apresentadas por MOREIRA (1980) e MORAES e COSTA (1980). De acordo com estas concepções, o espaço é a própria formação social por ser a condição da produção e da reprodução das classes sociais (MOREIRA, 1980); e a formação territorial constitui uma forma de criação de valor (MORAES e COSTA, 1980).

A aplicação empírica do conceito de formação espacial na geografia brasileira se dá principalmente através da utilização das categorias de função, processo, estrutura e forma. Estas categorias de análise são atributos da formação espacial e encon- 
tram-se integradas em uma totalidade sócio-espacial em movimento (SANTOS, 1992).

Os estudos urbanos de VASCONCELOS (1995) e SOUZA (1995) fazem uma abordagem da urbanização abrangendo os seguintes aspectos:

- a infra-estrutura, considerando as relações econômicas ao longo da história no caso específico do trabalho escravo (VASCONCELOS, 1995) e do trabalho assalariado (VASCONCELOS, 1995 e SOUZA, 1995) com seus conflitos e contradições;

- a super-estrutura, abordando o aparato político e ideológico do Estado e da Igreja (VASCONCELOS, 1995) ou somente do Estado (SOUZA, 1995);

- a inserção dos casos estudados na totalidade sócio-espacial, como no caso da inserção de Salvador nos diversos estágios da economia capitalista (VASCONCELOS, 1995) e da integração de São Paulo ao capitalismo industrial (SOUZA, 1995);

- as formas espaciais resultantes como a forte segregação espacial existente em Salvador (VASCONCELOS, 1995) e a verticalização espacial de São Paulo (SOUZA, 1995).

A concepção implícita no conceito de formação espacial também é utilizada para a abordagem de problemas sob uma ótica integradora dos processos sociais a processos espaciais. GONÇALVES (1995) considera a formação-espacial como um conceito necessário para a superação da dicotomia homem/natureza, pois os problemas sócio-ambientais têm sua origem em processos sócio-históricos. BERNARDES (1995), faz uma abordagem das transformações estruturais no espaço resultantes da introdução da técnica para entender que a ausência de mudanças não significativas nas relações sociais no caso estudado (a região do Norte Fluminense) são inerentes à sua posição periférica na divisão espacial do trabalho.

Portanto, pode-se considerar que se o conceito de formação espacial não se encontra restrito à Geografia brasileira, ele constitui mais uma concepção, um direcionamento teórico e metodológico. Esta concepção se materializa, principalmente, na abordagem da dialética-marxista com a valorização do processo histórico, das relações sócio-econômicas e das formas espaciais expressas neste processo. Este debate possui a possibilidade de ser enriquecido na medida em que novas realidades demandam o aperfeiçoamento e a adequação do conceito.

\section{Novas Perspectivas para o Conceito}

Ao finalizar sua análise sobre a formação espacial de Los Ângeles, Soja (1993) expõe as limitações de uma abordagem totalizante. As estruturas apresentadas (a ordem econômica, a estrutura nodal instrumental e a divisão espacial do trabalho), assim como a organização do sistema urbano, têm sido encobertas por uma visãó mistificadora. Este processo resulta de uma crescente "desconstrução conservadora, 
acompanhada por uma entorpecedora despolitização das relações de conflitos fundamentais de classe e sexo" (SOJA, 1993). Sob esta perspectiva, torna-se necessária uma revisão conceitual das concepções inerentes ao espaço, considerando a complexidade dos processos sócio-espaciais atuais.

Para Soja (1993), a principal limitação a uma abordagem totalizante constitui o número demasiado de fatores atuantes no espaço, cujo significado está sujeito a várias interpretações impossibilitando a construção de um materialismo histórico completo.

Neste sentido, as perspectivas de aplicação do conceito de formação espacial parecem se definir em dois tipos de utilização que se encontram interrelacionados. $\mathrm{O}$ primeiro relativo ao aspecto teórico conceitual e o segundo inerente à abrangência da análise.

No caso de aspecto teórico-conceitual são consideradas as novas interpretações do que vem a ser formação-espacial (ou formação sócio-espacial) e quais são seus componentes. Di Méo (1991) identifica a dinâmica político-ideológica e a dinâmica geo-econômica como responsáveis pela construção complexa do espaço. Neste contexto, as principais modalidades de objetivação do espaço constituem: a políticoadministrativa, a sócio-econômica e a modalidade estritamente social baseada em laços de afetividade.

Enquanto a modalidade político-administrativa atua principalmente nas escalas nacional e regional, a modalidade sócio-econômica e a modalidade social atuam principalmente na escala local (DI MÉO, 1991). Neste sentido, as formações sócioespaciais atuais são dotadas de uma dinâmica muito mais complexa para as quais a modalidade político-administrativa não possui capacidade de acompanhar a sua evolução. Di Méo concentra sua atenção em processos cotidianos, os principais responsáveis pelas mudanças.

$\mathrm{O}$ aspecto relativo à abrangência da análise constitui a necessidade de delimitar quais os elementos a serem abordados através do conceito de formação espacial. Os trabalhos apresentados por MORAIS (2000) e SANTOS e SILVEIRA (2001) demonstram o aperfeiçoamento do conceito no sentido de trazer uma nova compreensão da totalidade sócio-espacial.

MORAES (2000) propõe o fortalecimento de uma perspectiva histórico-dialética através de uma contribuição geográfica para o conhecimento da formação social brasileira. A primeira fase da colonização do Brasil é analisada como a "materialização de formas de sociabilidade reinantes numa paisagem e numa estrutura territorial" os quais são responsáveis pela constituição de um território através de um processo cumulativo em contínuo movimento. $\mathrm{O}$ bandeirante torna-se, portanto, o principal ator neste processo, integrando dialeticamente uma função na formação territorial brasileira de apropriador de espaços e estabelecedor de um novo padrão de relações sócio-econômicas.

SANTOS e SILVEIRA (2001) tratam da formação espacial brasileira através da integração das estruturas sócio-econômica, política e espacial na categoria de território. A identificação do espaço com o território representa a necessidade do esforço 
de uma análise empírica e sistematizada de sua constituição. O método utilizado remete à dialética marxista, na qual são periodicizados os diversos sistemas técnicos com seus modos de organização e regulação:

“...a divisão territorial do trabalho envolve, de um lado, a repartição do trabalho vivo nos lugares e, de outro, uma distribuição do trabalho morto e dos recursos naturais. Estes têm um papel fundamental na repartição do trabalho vivo. Por essa razão, a redistribuição do processo social não é indiferente às formas herdadas, e o processo de reconstrução paralela da sociedade e do territóro pode ser entendido a partir da categoria de formação sócio-espacial". (SANTOS e SILVEIRA, 2001:20)

Pode-se compreender, portanto que o conceito de formação espacial ainda constitui um instrumento a ser utilizado na Geografia. Embora suas limitações resultem da própria complexidade da totalidade sócio-espacial, estas mesmas apresentam possibilidades do enriquecer o conhecimento.

\section{Considerações Finais}

Tratar da gênese e da contribuição do conceito de formação espacial para a Geografia implica fazer uma análise da evolução histórica do pensamento geográfico. Este processo demonstra que o desenvolvimento de teorias, métodos e conceitos na Geografia depende de uma conjugação de fatores como posição ideológica e contexto histórico e geográfico. Em última análise, a história do pensamento geográfico pode ser entendida como um aspecto da história das ideologias em Geografia.

Toma-se como base o próprio conceito de formação espacial em si. Este conceito está intimamente ligado à Geografia Crítica. A formação espacial acaba por se constituir uma visão de grupo voltada para problemas específicos. Sob esta perspectiva, a concepção de ideologia se conecta à ciência. A visão de um grupo, com um determinado posicionamento político, desenvolve um arcabouço teórico-metodológico para a compreensão de uma realidade que lhe é própria e que o atinge.

Neste sentido, como se apresenta a realidade a ser entendida pelo conceito de formação espacial? Ela constitui o contexto da crise na Geografia, o qual não corre independente da crise da economia capitalista no fim do século XX. Não é por acaso que a formação espacial passa a atribuir uma referência teórica metodológica para os problemas de sociedades marginalizadas ou países periféricos como o Brasil.

A eficácia do conceito persiste com a permanência dos problemas analisados. Estes decorrem das contradições e dos conflitos do modo de produção capitalista. A evolução histórica da totalidade sócio-espacial acentua, portanto, a necessidade de constante revisão e atualização do conceito de formação espacial.

O CONCEITO DE FORMAÇÃO ESPACIAL: SUA GÊNESE E SUA ONTRIBUIÇÃO PARA A GE-: OGRAFIA 
Resumo: Neste artigo é analisada a importância do conceito de formação espacial para a Geografia. O estudo divide-se em três partes: a primeira, trata da gênese do conceito, a segunda aborda a aplicação do conceito de formação espacial para a Geografia brasileira e a terceira e última parte apresenta as perspectivas para a utilização do conceito. O conceito incorpora concepções do materialismo histórico do estruturalismo correspondendo à dimensão espacial do conceito de formação econômica e social tendo sido estabelecido por Milton Santos em 1979, o conceito de formação espacial insere-se na Geografia Crítica, sendo utilizado principalmente como uma concepção ou um direcionamento teórico-metodológico para o estudo da estruturação do espaço em contextos histórico-geográficos específicos constituindo um instrumento ainda a ser utilizado na Geografia para o entendimento da totalidade sócio-espacial.

Palavras-chave: método, estruturalismo, formação espacial

Abstract: This article analyses the importance of the concept of spatial formation for Geography. The study is divided in three parts: the first one is about the concept's origin;, the second is about the application of the concept of spatial formation for the Brazilian Geography; , and the third and last part shows the perspectives for the concept's use. The concept has conceptions of the historic materialism and of the structuralism, being an spatial dimension of the concept of economic and social formation which was established by Milton Santos in 1979. The concept of spatial formation is related to the Critical Geography, being used mainly as a conception or an teorical-methodological directive for the study of the space structural formation in specific historical-geographical contexts being an instrument to be used in Geography for the understanding of the socio-spatial totality.

Keywords: method, structuralism, spatial formation

\section{BIBLIOGRAFIA}

BERNARDES, Júlia A. 1995. Mudança técnica e espaço: uma proposta de investigação in CASTRO, Iná E.; GOMES, Paulo C. \& CORREAA, Roberto L. Geografia: Conceitos e Temas. Rio de Janeiro: Bertrand Brasil.

DI MÉO, Guy. 1985. Les formations socio-spatiales ou la dimension infra-regionale em geógraphie in Annales de Geógraphie $\mathrm{n}^{\circ}$ 526. Paris: Armand Colin.

DI MÉO, Guy. 1991. L'Home, la Société, l'Espace. Paris: Antrophos.

GOMES, Paulo C. 1996. Geografia e Modernidade. Rio de Janeiro: Bertrand Brasil. GONÇALVES, Carlos W.P. 1995. Formação sócio-espacial e questão ambiental no Brasil in BECKER, Bertha K. et al (orgs.) Geografia e Meio Ambiente no Brasil. São Paulo: Hucitec.

GREGORY, Derek. 1978. Ideology, Science and Human Geography. London: Hutchinson.

HAMLYN, D.W. 1987. Uma História da Filosofia Ocidental. Rio de Janeiro: Jorge Zahar.

HARVEY, David. 1997. Social Justice and the City. Baltimore: The Jonh Hopkins University Press, $3^{\text {rd }}$ edition.

MAMIGONIAN, Armen. 1996. A Geografia e a formação social como teoria e como método in SOUZA, Maria A.A. (org.) Mundo do Cidadão, um Cidadão do Mundo. São Paulo: Hucitec. 
MARX, Karl \& ENGELS, Frederick. 1986. The German Ideology. New York: International Publishers.

MORAES, Antonio C.R. 2000. Bases da Formação Territorial do Brasil: o Território Colonial Brasileiro no 'Longo' Século XVI. São Paulo: Hucitec.

MORAES, Antonio C.R. \& COSTA, Wanderley M. 1982. A Geografia e o processo de valorização do espaço in SANTOS, Milton (org.) Novos Rumos da Goografia Brasileira. São Paulo: Hucitec.

MOREIRA, Ruy. 1982. A Geografia serve para desvendar máscaras sociais in MOREIRA, Ruy (org.) Geografia: Teoria e Crítica. O saber posto em questão. Rio de Janeiro: Editora Vozes.

OLIVEIRA, Ariovaldo U. 1982. Espaço e tempo: compreensão materialista dialética in SANTOS, Milton (org.) Novos Rumos da Geografia Brasileira. São Paulo: Hucitec.

PRADO JÚNIOR, Caio. 1969. Formação do Brasil Contemporâneo. São Paulo: Brasiliense, $9^{\mathrm{a}}$ edição.

QUAINI, Massimo. 1979. Marxismo e Geografia. Rio de Janeiro: Paz e Terra.

SANTOS, Milton. 1992. Espaço e Método. São Paulo: Nobel, $3^{a}$ edição.

SANTOS, Milton. 1978. Por uma Geografia Nova. São Paulo: Edusp.

SANTOS, Milton. 1979. Sociedade e Espaço: a Formação Social como Teoria e como Método in SANTOS, Milton (org.) Espaço e Sociedade. Petrópolis: Vozes.

SANTOS, Milton \& SILVEIRA, Maria L. 2001. O Brasil: Território e Sociedade no Início do Século XXI. São Paulo. Record.

SODRÉ, Nelson W. 1986. Introdução à Geografia: Geografia e Ideologia. Petrópolis: Vozes, $5^{\text {a }}$ edição.

SOJA, Edward W. 1993. Geografias Pós-Modernas: a Reafirmação do Espaço na Teoria Social Crítica. Rio de Janeiro: Jorge Zahar.

SOJA, Edward W. 1980. "The socio-spatial dialetic" in Annals of American Geographers vol. 70, $\mathrm{n}^{\circ} 02$.

SOUZA, Maria A.A.1995. São Paulo: metrópole do Terceiro Milênio in BECKER, Bertha K. et al (org.) Geografia e Meio Ambiente no Brasil. São Paulo: Hucitec. 